\title{
A dualidade na inserção política, social e familiar do idoso: estudo comparado dos casos de Brasil, Espanha e Estados Unidos
}

\author{
Maria Inez Machado Telles Walter \\ Centro de Pesquisa de Opinião Pública \\ Universidade de Brasília
}

Resumo: $O$ artigo apresenta um estudo comparado da situação social, política, econômica e de saúde da população idosa do Brasil, Espanha e Estados Unidos. Foi feita uma discussão sobre o processo de mudança na estrutura de idades a partir da literatura dos três países. As análises de dados confirmaram as melhorias nas condições de vida do idoso e as mudanças em sua inserção social e em posições morais e políticas. Indicaram também que não há semelhanças ou diferenças entre os países que possam ser atribuídas à sua condição econômica ou à tradição cultural. A dualidade expressa uma transição nesse segmento, tradicionalmente visto negativamente e, hoje, considerado também como apoio econômico e familiar. Espera-se que se consolide a tendência de privilegiar o papel social positivo do idoso pela naturalização do envelhecimento e o estabelecimento de referências analíticas na própria velhice.

Palavras-chave: envelhecimento; família; gerontologia social; estudo comparado

Abstract: The paper presents a comparative study of social, political, economical, and health situation of aged population of Brazil, Spain, and United States. A discussion was made about changing process in age structure base don literature of the three countries. Data analysis confirmed improvements in aged people life conditions, and changing on social insertion and political and moral attitudes. Data indicated also that there are no similarities or differences among the countries which can be attributed to economic conditions, nor to cultural traditions. The duality expresses a transition in this segment, traditionally viewed in a negative way and, nowadays, also considered as economic and familiar support. The perspectives are that the aged people positive social role will be emphasized by naturalization of aging and by establishing de analytic references on aging itself.

Keywords: aging; family; social gerontology; comparative study

OPINIÃO PÚBLICA, Campinas, vol. 16, nº 1, Junho, 2010, p. 186-219 


\section{Introdução}

A mudança na estrutura etária das populações, pelo aumento da quantidade e da proporção de pessoas de mais idade, fez com que esse segmento social não mais pudesse ser circunscrito às esferas privada e familiar, emergindo como questão política, social e de saúde pública. Isso se deve ao fato de as pessoas estarem vivendo mais, um fenômeno que já vinha se consolidando nos países europeus e nos Estados Unidos, mais recente e acelerado no Brasil, embora também naqueles países tenha aumentado seu ritmo nas últimas décadas. Somado à queda nos índices de fecundidade e a taxas de migração em diferentes combinações, o fenômeno vem alterando a estrutura etária das sociedades, em um processo conhecido como envelhecimento da população. $O$ aumento da quantidade absoluta e relativa das camadas de mais idade modificou de forma determinante a pirâmide etária e colocou o idoso no foco de atenção dos serviços públicos e da sociedade.

Muito se discute a respeito dos impactos do aumento do tempo de vida sobre os sistemas previdenciários, a saúde pública e, mais recentemente, as configurações familiares. O idoso tem sido apontado como um apoio familiar da maior importância, não apenas pela renda de suas aposentadorias, mas também por contribuir na organização da família, por exemplo, no apoio aos cuidados com o lar e com crianças pequenas. É fato também que as condições de saúde dos idosos têm melhorado, e isso permite uma participação mais prolongada em diversos aspectos da vida social.

Assim, ao mesmo tempo em que vai diminuindo inexoravelmente sua independência para a vida cotidiana, devido a limitações de ordem física e de saúde, o idoso tem reforçado sua importância na sociedade e, em muitos casos, postergado sua condição de arrimo da família, principalmente quando se torna a única fonte segura de ingresso monetário sistemático. 0 momento presente reflete perfeitamente uma transição. Se antes o idoso era visto como um peso para a sociedade, alguém dependente social e economicamente, sem saúde e sem função, hoje essa condição persiste, mas convive com idosos ativos e participativos, até mesmo imprescindíveis para o bem-estar social. Cabe, portanto, refletir sobre a dualidade que cerca o papel social da terceira idade - responsável pela família e dependente dela - o que se propõe realizar neste artigo por intermédio da análise dos casos brasileiro, espanhol e americano.

Os dados da pesquisa internacional World Values Survey (WVS) foram usados para verificar, comparativamente a outros grupos de idade, os valores sociais e políticos do idoso, revelando diversos aspectos de sua inserção social. Também se realizou uma abordagem comparativa entre os três países, que foram as peças para 
construir um apanhado sócio-político do idoso, ressaltando as semelhanças e diferenças na abordagem do tema em países com características tão distintas quanto Brasil, Espanha e Estados Unidos.

A questão do idoso vem sendo estudada a partir de abordagens filosóficas, psicológicas e médicas há mais tempo do que sob o ponto de vista político e social. O envelhecimento é um processo complexo, "heterogêneo e individualizado, que depende da interação entre fatores biológicos, sociais, psicológicos, econômicos, ambientais, históricos e culturais" (MASCARO, 2004, p. 89). Já vai longe o tempo em que o idoso era um assunto das famílias, com papel social restringido por conceitos e estereótipos altamente negativos.

A crescente importância atribuída ao idoso se revela na literatura, em diversas áreas da academia e na temática das políticas sociais. Hoje já se consolidou até mesmo uma nova terminologia para referir o idoso, que procura não ser depreciativa e sim de maiores valorização e respeito. O surgimento de categorias como a terceira idade contribuiu definitivamente para repensar conceitos e atitudes.

A primeira parte deste artigo discute teoricamente o envelhecimento e a mudança na estrutura de idade das populações. Em seguida, realiza uma comparação entre Brasil, Espanha e Estados Unidos, através de análises de dados de diversas fontes, e comparando-se o segmento dos idosos com os outros grupos de idade dentro de cada país. Os resultados pos países também foram comparados entre si. Como se verá, ocorreram resultados semelhantes entre os grupos de idade em alguns temas e em outros, não, sem possibilidade de uma classificação que separe idosos dos demais por algum fator ou alguma dimensão. Da mesma forma, diversas combinações ocorreram nas comparações entre países, também sem recorrências que permitam agrupá-las ou separá-las.

\section{A discussão teórica sobre o envelhecimento}

Diferentes interpretações na literatura são confrontadas, na discussão sobre o processo de mudança na estrutura de idades nas populações, destacando suas contribuições e também refutando algumas das teses mais comuns ligadas ao que se chama de envelhecimento populacional. As fontes para a discussão conceitual aqui abordada concentraram-se na produção dos três países tratados neste artigo. A forma de abordar o envelhecimento nessa literatura consultada é mais frequentemente negativa, principalmente quando se considera o potencial impacto do aumento da idade média da população ${ }^{1}$ sobre o equilíbrio financeiro dos sistemas previdenciários, antecipando o agravamento do déficit entre contribuintes

${ }^{1}$ O termo "envelhecimento populacional" será evitado por razões conceituais que estão discutidas mais adiante. 
e beneficiários e a sobrecarga na saúde. São constantes as prospecções econométricas sobre o perigo do desequilíbrio das finanças públicas considerando as taxas históricas daquele aumento da idade média da população e a evolução dos dados econômicos². Também são constantes as ponderações acerca dos impactos negativos sobre as famílias, os conflitos intergeracionais ${ }^{3}$ e o risco do abandono face à redução da quantidade de filhos e à inserção da mulher no mercado de trabalho ${ }^{4}$. Em suma, os aumentos na quantidade e na proporção de idosos são constantemente abordados como fatos inexoráveis com impactos negativos na economia e na sociedade.

Na literatura brasileira e na americana, o que foi encontrado de positivo, ou melhor, menos negativo, relaciona-se a alertas sobre os preconceitos diversos em relação à pessoa do idoso, como contraponto à cultura da juventude, e sobre os esforços inglórios de retardar o processo de envelhecimento e até de negá-lo. 0 avanço da idade não significaria, portanto, apenas perdas inerentes ao envelhecimento e nem a desistência de participar ativamente de atividades cotidianas. E nem poderia ser assim, pois o aumento da expectativa de vida implica mais tempo de vida com saúde e maior preservação das capacidades, adiando as limitações causadas pelo envelhecimento.

Através da literatura, por sua vez, obeteve-se subsídio para uma ampliação conceitual. Além de ultrapassar as explicações exclusivamente demográficas, com base em taxas de natalidade, mortalidade e migrações, o aumento da idade é considerado, por exemplo, como um avanço social em geral, a "democratização da sobrevivência geracional até a maturidade" (PÉREZ DÍAZ, 2005, p. 7), um produto da modernidade, a prova material da melhoria das condições de vida em geral (PÉREZ DÍAZ, 2003, 2005, 2006). Não é a queda da natalidade que provoca o aumento da idade média, mas a queda da mortalidade em todas as idades que, por sua vez, permite reduzir a quantidade de filhos e dedicar mais e melhores cuidados a eles. A queda da natalidade seria, portanto, uma consequência da queda da mortalidade em todas as idades. Essas, sim, podem ser consideradas como abordagens alternativas e positivas, um contraponto claro às perspectivas mais comuns de discussão do envelhecimento. Muito das análises negativas derivam do

\footnotetext{
2 Ver, por exemplo, em Queiroz et al, 2007; Najberg \& Ikeda, 1999; Camarano, 2002; Paiva \& Wajman, 2005; Wong \& Carvalho, 2006; Envejecimiento en Espana (disponível em <http://www.comunidadmayor.com/gerontol/demo_enveEspanha.asp> acesso em: [6 fev., 2008]) ONU, 2006; Wise, 2004.

${ }^{3}$ Nesse tema é discutida distribuição do investimento social dos governos, que estaria favorecendo os idosos em detrimento de outros segmentos gerando, como consequência, um conflito intergeracional. No caso do Brasil, o argumento é que a população ainda é predominantemente mais jovem, e que os últimos investimentos reduziram mais fortemente a pobreza dos idosos do que de mulheres e crianças. Ver principalmente em Goldani, 2004.

${ }^{4}$ Ver, por exemplo, Goldani, 2004; Pérez Díaz, 2003, 2005; Lopes, 2006.
} 
conceito negativo da própria velhice, que se transfere para o contexto devido ao aumento da concentração de pessoas idosas.

Pérez Díaz considera que a mudança na configuração demográfica é o reflexo de uma "revolução reprodutiva" que resultou do aumento de "eficiência reprodutiva" (PEREZ DÍAZ, 2005, p. 11). Para ele, trata-se de uma maneira melhor de manter as populações humanas, muito mais eficiente no rendimento obtido de cada nova vida trazida ao mundo. Na história da humanidade, a fecundidade sempre foi alta para garantir a sobrevivência "da espécie", em um tipo de compensação para as altas taxas de mortalidade, não apenas infantil, mas durante toda a vida, para que houvesse membros que garantissem a reprodução e a continuidade. Todavia, trata-se de um sistema ineficiente, pois, mesmo assim, a população não aumentava muito.

Ao contrário, o que fez a diferença foi o prolongamento da vida, diminuindo a mortalidade em todas as suas fases. A democratização da sobrevivência mínima até a idade reprodutiva já é um fator de êxito reprodutivo por si, pois as populações aumentam ainda que a fecundidade diminua, uma vez que as pessoas passam muito mais tempo vivas. Esse êxito se retroalimenta porque distribui melhor o trabalho de ter filhos, antes limitado à pequena parte sobrevivente de cada geração. Isso, por sua vez, permite descendências menos abundantes, às quais se pode dedicar mais cuidados e recursos, o que redunda em maior sobrevivência. Um círculo virtuoso, em suma, que conduz à exitosa dinâmica populacional atual e, é claro, a uma configuração populacional completamente nova.

Outra interpretação para as mudanças demográficas é a chamada "teoria da evolução tecnofisiológica". Proposta por Robert Fogel (2001, p. 3, 2004, p. 35-36) e Dora Costa ${ }^{6}$, a evolução tecnofisiológica é o resultado da sinergia entre melhorias tecnológicas e fisiológicas, que produziu uma forma de evolução humana que é biológica, mas não genética, nem rápida, nem culturalmente transmitida e não necessariamente estável. Esse processo ainda está em curso tanto nos países ricos e como nos em desenvolvimento. As medidas corporais aumentaram, assim como a capacidade dos organismos vitais do homem. Isso contradiz a teoria de que há um capital inicial de saúde inato que vai se depreciando ao longo da vida. Para aqueles autores, não apenas esse estoque inicial vem aumentando como o grau de depreciação depende do tamanho do investimento na saúde e da tecnologia. Porém, o prolongamento da vida depende somente em parte dos avanços tecnológicos, pois reflete também melhorias fisiológicas que são devidas a melhorias tecnológicas na produção de alimentos, nas práticas de saúde pública, na higiene pessoal, nas dietas e nas intervenções médicas.

\footnotetext{
${ }^{5}$ Tradução livre para "techonofisio evolution theory". Ver Waite, 2004; Fogel, 2004.

${ }^{6}$ Dora Costa foi citada pelo autor nas duas obras referenciadas.
} 
Trata-se de duas contribuições importantes, na medida em que trazem outros elementos à consideração e ampliam a problematização das mudanças demográficas. Embora de maneiras bastante diferentes, estabelecem inter-relações entre fatores subjetivos e objetivos que teriam ocasionado a configuração populacional que se tem hoje.

$\mathrm{Na}$ interpretação de Pérez Díaz, por um lado, há claramente uma preponderância culturalista, não necessariamente racionalizada, mas que traz em seu bojo uma mudança cultural, uma nova forma de ver e tratar os descendentes e até a própria vida - esse é o lado subjetivo - que redunda em mais eficiência no processo de reprodução global. Fogel, por outro lado, traz dados, modelos de tendências e fatores objetivos que dão fortes argumentos explicativos que fundamentam o aumento da expectativa de vida. Seu trabalho é forte em análises sobre doenças crônicas e gastos públicos em saúde, que são aspectos fundamentais quando se fala em aumento de idade média. Entretanto, Fogel deixa de tratar dos outros dois fatores que incidem sobre a configuração populacional, a natalidade e a migração. Essa não é mesmo sua proposta, mas a ausência desses dois fatores deixa um vácuo explicativo para o outro lado do fenômeno, a alta queda da natalidade. Além disso, na sua visão, essas mudanças não são culturalmente transmitidas.

Nesse ponto não é possível deixar de assinalar que todas as mudanças que Fogel chama de controles sobre o ambiente são fortemente culturais, embora ele afirme o contrário. Da produção de alimentos às práticas de saúde pública, passando pela higiene pessoal, tudo deriva da popularização de informações científicas e tecnológicas que impliquem na absorção de novos hábitos pessoais, mas que sejam disseminadas coletivamente para surtir os efeitos que mudaram os dados epidemiológicos e de saúde pública, incluindo o saneamento básico. Assim, o desenvolvimento científico e tecnológico, ao que Fogel atribui apenas parte da explicação para o prolongamento da vida, não ocorreu de forma dissociada de fortes e aceleradas mudanças culturais, que o autor não trata nem tangencialmente.

O discurso sobre as mudanças demográficas em muitos casos é dúbio, e a discussão muitas vezes se encaminha para prescrições, formas e alternativas de combater a velhice e até para a possibilidade de "envelhecer sem ficar velho" (PRADO \& SAYD, 2006, p. 495). Fala-se em usar o saber acumulado como oportunidade de "explorar novas identidades, realizar projetos abandonados em outras etapas da vida, estabelecer relações mais profícuas com o mundo dos mais jovens e dos mais velhos" (DEBERT, 1997) e em oportunidade de "recomeço em que novas identidades podem ser exploradas de maneira criativa" (DEBERT, 2003, p. 154). Mesmo reconhecendo a dificuldade de criticar estereótipos sem criar novos em substituição, fato para o qual Debert chama a atenção repetidamente assim como Leibing (2005), os trechos destacados são exemplos de prescrições eivadas 
de cobranças de atitudes. Afinal, por que é necessário criar "novas identidades", "recomeçar", ser "mais criativo"? Por que as identidades cultivadas ao longo da vida não podem simplesmente continuar seu processo? O que muda com o tempo são as condições objetivas e funcionais e a forma de se encaixar na sociedade. Isso pode ser incorporado à identidade que foi sendo paulatinamente construída, em uma continuidade.

A tentativa de mostrar o lado bom do envelhecimento, a conquista da experiência, da sabedoria e da tranquilidade, acaba configurando a velhice como uma ruptura necessária. Só que não necessariamente a pessoa chega à velhice tendo abandonado projetos, ou se os abandonou pode ter sido por deliberação, por motivos razoáveis ou apropriados para a ocasião, não necessariamente deixaram de ser estabelecidas relações profícuas entre o mundo dos mais jovens e dos mais velhos e não necessariamente o idoso deixou de usar a criatividade ao longo de toda sua vida. Assim, a tentativa de fuga dos estereótipos acaba por reforçá-los.

Não se discute a necessidade de refletir sobre o envelhecimento nos níveis individual e coletivo. A grande contribuição da gerontologia social é difundir a reflexão sobre a velhice. Pode-se dizer que a atual geração de idosos formou-se refletindo bem menos sobre essa etapa da vida, pois era bem menor o grau de conhecimento sobre os processos físicos e psíquicos relacionados ao envelhecimento e a importância política só emergiu recentemente. Da mesma forma, os papéis sociais alargaram-se muito nas últimas décadas, principalmente para as mulheres, a família e, como mais um dos subprodutos, os idosos. Essa mudança visível nas sociedades teve, sem dúvida, seus desdobramentos na cultura, nas práticas sociais e, sobretudo, nos conceitos.

Intuitivamente, sabemos o que significa envelhecer, ficar velho. Ao mesmo tempo, determinamos tacitamente que é inadequado utilizar o termo "velho" para caracterizar pessoas. Convencionou-se utilizar eufemismos para se referir a pessoas com idade avançada. Em todos os idiomas, é usual adotar sinônimos que se apresentam como termos que não são considerados depreciativos. Aged, elderly ou senior em inglês, mayor ou anciano em espanhol, e idoso em português são alguns exemplos além, é claro, da "terceira idade". O prurido para fazer referência aos idosos demonstra de antemão uma dificuldade para abordar o tema do envelhecimento no nível individual e essa é a raiz da dubiedade dos discursos, já que os eufemismos representam, ao mesmo tempo, uma diferenciação, uma valorização, e uma negação da condição de envelhecido e um uso quase inevitável do termo jovem para se referir ao "envelhecimento bem sucedido". Entretanto, o mesmo não ocorre no que se refere às populações. O dito "envelhecimento

${ }^{7}$ Ver, por exemplo, Debert, 2003, Leibing, 2005 e Prado \& Sayd, 2006, entre outros. 
populacional" é sobejamente utilizado, o que, por sua vez, conforma o discurso negativo predominante.

No nível individual, uma marca da literatura é a dificuldade de fugir do paradoxo de analisar o envelhecimento sem fazer referência ao termo velho ou qualquer de seus eufemismos. Exemplo disso é a separação da idade cronológica do que seriam outras idades, "biológica", "psicológica", entre outras. Expressões como "manter-se jovem apesar da idade", "atitude jovem", "jovialidade" amarram o referencial do discurso na juventude. Em muitos casos, as análises não desvinculam a velhice do jovem a despeito de preconizarem, corretamente, o combate aos preconceitos e às percepções negativas ou depreciativas.

Leibing (2005, p. 18) pondera que o emprego desses sinônimos tem como objetivos declarados, justamente, o repúdio aos estereótipos negativos associados ao envelhecimento é a atribuição de mais poder aos idosos. Entretanto, a autora chama a atenção que, ao mesmo tempo, cria-se um novo estereótipo de comportamento para a "terceira idade" que exige independência, força de vontade, busca constante de atividades sociais e de diversão. E quem não se enquadra nessa moldura muda para a categoria da "quarta idade", que inclui os mais idosos ou que precisam de cuidados, têm problemas de saúde ou perdas funcionais que os impeçam física, psíquica ou emocionalmente de agir e viver como o grupo chamado de "terceira idade". Ao idoso não é dada a opção de viver de maneira mais introspectiva e com poucas atividades coletivas, mesmo que isso seja uma opção pessoal. Isso é confundido com depressão, tristeza e desajuste, enfim, com ficar velho.

Por outro lado, apesar de se saber intuitivamente o que é ficar velho, é difícil definir quais são as características do idoso. Diferentemente das crianças e adolescentes, e até mesmo dos adultos, pessoas acima de 60 ou 65 anos possuem características pessoais tão diversificadas quanto é possível em um grupo que pode conter diferenças etárias de mais de 30 anos. Entre os idosos encontram-se pessoas num gradiente que vai desde aquele que desempenha todas as suas atividades de maneira independente, trabalha, tem renda, boa saúde, relações familiares e sociais, até a pessoa totalmente dependente de cuidados de terceiros, com necessidades físicas e psíquicas extremas, que não se relaciona mais familiar ou socialmente por impedimentos de saúde, por exemplo. Em cada ponto desse gradiente, extremamente matizado, pois todas as combinações de condições físicas, mentais e sociais são possíveis, a idade das pessoas pode ser extremamente diversificada. É possível que uma pessoa aos 70 anos ocupe qualquer de seus extremos, mesmo reconhecendo ser mais provável que o avanço da idade agrave os empecilhos a uma vida semelhante à de um adulto saudável. Essa dificuldade não se reflete somente na formulação dos conceitos sobre o idoso mas, sobretudo, na 
formulação de políticas para esse segmento, pois as características, necessidades e carências apresentam altíssimo grau de variabilidade.

No que diz respeito à população, o termo mais comum é mesmo o envelhecimento. Para Pérez Díaz (2005), entretanto, o termo "envelhecimento da população", além de não ter sentido semanticamente, visto que, na verdade, as populações não envelhecem porque não têm idade, traz em si uma carga de negatividade que induz a preconceitos e a interpretações apocalípticas que transferem para a sociedade as mazelas percebidas no envelhecimento individual. Para o autor, se o objetivo é refletir sobre as consequências dessas mudanças na estrutura de idade das sociedades, não é suficiente supor que os atributos e repercussões da velhice individual serão os mesmos que ocorrerão na velhice social.

Esse autor pontua que a mudança na estrutura etária pode ocorrer por diversos fatores, não apenas pela queda da natalidade associado ao aumento da expectativa de vida. Essa é a visão predominante, mas há casos como os de pequenas cidades que viveram um processo acentuado de emigração de jovens em busca de oportunidade de trabalho, por exemplo, como ocorreu no interior rural da Espanha. Por outro lado, as nações mais envelhecidas estão entre as maiores receptoras de imigrantes, razão pela qual sua estrutura de idade não teria proporção ainda maior de idosos. Isso significa que a questão da mudança na estrutura de idades não é única e nem ocorre da mesma maneira e nem pelas mesmas causas. As visões estáticas são reducionistas e se prestam à legitimação do discurso do caminho para o desastre.

Em sua análise da "revolução reprodutiva", Pérez Díaz considera que a queda de natalidade seria, portanto, uma das consequências, e não uma das principais causas das mudanças demográficas. É uma mudança qualitativa de grande escala na sobrevivência e na reprodução humanas "que ainda deve acentuarse sensivelmente antes de alcançar seu grau máximo, e já não tem volta" (PERÉZ DIAZ, 2005, p.11).

O autor considera que as principais causas relacionam-se ao aumento da vida em todas as faixas de idade, e que esse processo não é tão recente no caso da Europa, sobretudo na França, tendo se iniciado ainda no século XIX. Tanto é assim que, já no início do século XX, houve análises que anteviam problemas tributados à queda da natalidade ${ }^{8}$.

Trata-se, sem dúvida, de uma análise diferenciada e muito mais complexa, que desmistifica as prospecções negativas e traz elementos novos para compreender a conformação etária das sociedades de quase todo o mundo. Considera-se de suma importância e ilustrativa da ambiguidade que caracteriza a

8 Pérez Díaz cita publicações datadas de 1907 e 1928. A mais antiga citação, de 1898, é a "Alliance nationale pour l'acroissement de la population française", trabalho considerado como um "autêntico lobbie patriótico-natalista" (PÉREZ DÍAZ, 2005, p. 2). 
literatura sobre o tema do envelhecimento a contradição conceitual que aponta Pérez Díaz, qual seja, a de que viver mais é bom para o indivíduo, mas não para a sociedade (PÉREZ DIAZ, 2005, p. 13).

Um dos pontos mais importantes de sua abrangente análise é argumentar contrariamente às previsões catastróficas presentes na literatura, com fatos e dados atuais, desconstruindo, ponto a ponto, algumas das visões correntes sobre as consequências do dito "envelhecimento populacional". Para Pérez Díaz, São previsões negativas que não se verificaram.

A decadência prevista das sociedades não ocorreu. A degradação social da velhice com o aumento dos anos de deficiências não houve, tendo ocorrido o contrário. O nível de bem-estar dos idosos aumentou. O autor cita o caso dos Estados Unidos, onde os idosos formavam, tradicionalmente, o grupo dos mais pobres e a melhoria das condições desse grupo foi mais acelerada do que a de outros, assim como ocorreu no Japão e na Espanha. No Brasil, não foi diferente. Segundo Goldani (2004, p. 211), as transferências de recursos aos idosos significaram uma redução mais acentuada dos níveis de pobreza do que em outros grupos, como mulheres e crianças.

A crise na família tributada ao aumento da presença dos idosos também não ocorreu. Ao contrário, os idosos ganharam importâncias econômica e afetiva. A quantidade de idosos chefes de família tem aumentado ano a ano, assim como a importância de seus rendimentos para o bem-estar de suas famílias. Isso resulta da expansão da abrangência do sistema previdenciário e das aposentadorias não. contributivas que, a despeito de todos os questionamentos sobre o grau de justiça desses benefícios, ocasionaram melhoria nos indicadores sociais do segmento de idosos no Brasil.

Previa-se um retrocesso na igualdade de gêneros devido ao sacrifício pessoal e profissional da mulher, tradicionalmente encarregada dos cuidados com os idosos de suas famílias. Entretanto, as taxas de ocupação e escolaridade da mulher aumentaram ao longo do tempo, o que foi imprevisto. Assim, Pérez Díaz afirma para a Espanha e outros países economicamente desenvolvidos também é uma realidade no Brasil. O mercado de trabalho caminha para o equilíbrio de gêneros e as diferenças salariais têm caído, implicando o aumento relativo dos salários das mulheres ao longo do tempo. Ademais, escolaridade das mulheres já superou a dos homens (PNUD Brasil, 2007).

Cabe observar que a expectativa de que a mulher se sacrifique para cuidar de seus familiares idosos é uma percepção datada, que não leva em conta outras soluções que já são realidade em países como a Espanha. As políticas públicas abrangeram o desenvolvimento de diversas estruturas de apoio ao idoso que, mesmo contando com a parceria da sociedade, principalmente das famílias, têm como finalidade dar a devida atenção ao idoso dependente de cuidados especiais 
(RODRIGUES ÁVILA, et al 2007). Essas previsões também não levam em conta que as condições de saúde dos idosos têm melhorado globalmente e que o grau de conhecimento sobre os males inerentes ao envelhecimento funciona como um facilitador e um difusor de opções para prover os cuidados necessários.

Assim, a piora na situação de bem-estar das outras idades por ter que cuidar de mais idosos e por mais tempo não passar de uma falácia, pois a melhoria no bem-estar dos idosos é essencialmente um fato positivo. Previa-se um "conflito intergeracional", derivado da disputa por recursos públicos, por postos de trabalho e outros fatores que caracterizariam em si um problema devido ao aumento na quantidade e na proporção de idosos nas sociedades. Essa é uma discussão ainda presente, principalmente para casos como o Brasil, com altas taxas de desigualdade social que ampliam a importância da distribuição dos recursos sociais. Há autores que consideram que os idosos foram privilegiados em relação a outros grupos de idade (ver, por exemplo, Goldani, 2004). Mesmo assim, não foram encontradas referências que comprovem que a melhoria mais acentuada dos indicadores sociais referentes aos idosos ocorreu em detrimento de outros grupos, apenas que os avanços dos demais foram menores, mas também foram positivos.

O ponto a que se refere Pérez Díaz sobre o dito conflito intergeracional é importante do ponto de vista analítico. Para ele, só se pode falar em injustiça intergeracional comparando as gerações na mesma idade. O autor, afirma apenas que basta comparar as condições de quem tem 15 anos hoje com quem tinha a mesma idade há 50 anos em termos de atenção, recursos, formação e bem-estar (PEREZ DÍAZ, 2005, p.16). Mais uma vez, suas ponderações podem ser aplicadas ao caso brasileiro. Os indicadores sociais vêm melhorando sistematicamente a despeito da perversa e persistente segregação social que marca o Brasil. Além do aumento da expectativa de vida, vêm melhorando todos os indicadores referentes à saúde, à educação e até mesmo à pobreza. Não é possível deixar de considerar que ainda há muito a conquistar para que o Brasil possa se tornar um país justo, mas, embora importante, tal ressalva, não desqualifica o argumento de que o apoio ao segmento idoso não contribui para aprofundar a injustiça social ou para alimentar um conflito intergeracional no Brasil.

Outro ponto diz respeito às previsões de que o bem-estar geral e das instituições seria afetado negativamente. Pérez Díaz (2005) considera que o discurso sobre a crise previsível dos sistemas públicos de pensões ou de saúde, e dos Estados de Bem-Estar em geral, faz parte dos fundamentos da reforma neoliberal dos anos 1980 e serviu como justificativa de privatização dos sistemas públicos de pensões. No caso da Espanha, o autor afirma que esse colapso não ocorreu, e que se deu justamente o contrário. As caixas de pensão nunca faturaram tanto e a realidade tratou de desmentir essa previsão. 
O sistema previdenciário brasileiro é um fator complexo, pois constitui também de um importante instrumento de política social (NAJBERG \& IKEDA, 1999). Após a Constituição de 1988, que instituiu benefícios de natureza nãocontributiva, ocorreu um peso nas despesas que agravou o equilíbrio financeiro e cuja solução não é trivial. Os sucessivos governos têm adiado as reformas mais profundas para dar soluções mais duradouras ao déficit previdenciário. Por isso é difícil concluir sobre o peso das aposentadorias para o desequilíbrio do sistema previdenciário brasileiro. Esse é o único ponto sobre o qual os dados e as projeções não permitem eliminar as previsões mais negativistas para o caso brasileiro.

Até aqui, procuramos abordar os temas relacionados às análises de dados que serão apresentadas neste artigo, bem como situá-las teoricamente. A proposta de trabalhar a dualidade na inserção política, social e familiar do idoso em perspectiva comparada dos casos de Brasil, Espanha e Estados Unidos foi introduzida destacando a dubiedade do discurso que cerca o processo de envelhecimento desde o nível coletivo, social e político, até o individual, social e familiar.

Considera-se que a família é uma das dimensões da inserção social, mas que é necessário tratar dela de maneira destacada, pois é o nível mais básico nas inter-relações primárias que envolvem o idoso. Tradicionalmente, o idoso era um problema exclusivo da e para a família. À medida que aumenta sua participação proporcional e quantitativa, expande-se sua importância como segmento social e merecedor de atenção de governos, que respondem por meio de políticas sociais focalizadas, e objeto de análises sociológicas.

A gerontologia social, assim como a geriatria, ainda caminha para estabelecer uma parceria analítica que reflita sobre o envelhecimento de maneira articulada e não apenas como problema de saúde, individual e pública, ou como pessoas ou grupo que já não têm mais importância para a sociedade, seja do ponto de vista de serem ou não economicamente produtivos ou de também atuar oferecendo soluções, e não apenas como fonte de problemas na sociedade. Alguns autores mencionam a dificuldade de estabelecer a gerontologia como campo de conhecimento, seja por causa de dificuldades teóricas básicas, como a definição do objeto científico, seja pelo pouco tempo de produção nesse tema, ainda considerado embrionário (PRADO \& SAYD, 2006).

Por que dualidade? Porque o aparecimento do idoso como categoria social é recente. Hoje o idoso desempenha um duplo papel, o de problema e o de solução. Se antes era mais problema, hoje já se equilibra como solução, enquanto outros grupos sociais representam mais soluções, como os adultos. Crianças e adolescentes representam mais problemas, mas isso é considerado como natural, ao contrário do idoso. 
A dualidade pode ser uma transição para a desmistificação, antevendo que algum dia sua inserção social, na quantidade e na proporção que for, seja naturalizada e que seu papel seja percebido como parte integrante da dinâmica social. Quando desaparecerem os últimos vestígios de rejeição ao envelhecimento individual e social, e quando as mudanças não forem mais interpretadas como perdas, mas apenas como o que são: mudanças, diferenças. As limitações físicas devem implicar adaptações e evolução para outras formas de viver e de se inserir na sociedade.

Isso implica amadurecimento da própria sociedade, que não mais rejeitará o que é inexorável e absorverá o envelhecimento como natural, quando cessarão as comparações com os mais jovens e o referencial da idade avançada estará nessa própria fase, não nas fases anteriores.

Este artigo pretende colaborar com a discussão conhecendo melhor o idoso sob o ponto de vista de suas percepções sobre a própria condição e analisando como se dá a sua inserção política, social e familiar nesses três países. Deve-se verificar o quanto a visão do idoso sobre a sociedade e a política difere de outros segmentos sociais. E em que medida os três países distinguem-se nessas questões, e o quanto e como evoluíram nos últimos anos.

\section{Idosos e não-idosos: os casos de Brasil, Espanha e Estados Unidos}

Os primeiros tópicos dessa seção incluem análises sobre temas relacionados a condições físicas, emocionais e de inserção social a partir de dados de saúde, educação, inserção no trabalho, fontes de renda, papel familiar, determinação de graus e tipos de interdependência social. Em seguida, tratados dados sobre valores sociais, morais e políticos dos grupos idosos. Com essas análises, busca-se compor um quadro comparativo da inserção e das percepções do idoso sobre sua própria condição e examinar sua visão sobre diversos aspectos da sociedade e da política, possíveis diferenças dos demais segmentos sociais, e o quanto e como evoluíram ao longo do tempo.

A principal fonte de dados é a base mundial do World Values Survey (WVS) ${ }^{9}$. Também foram utilizados dados de fontes oficiais dos três países ${ }^{10}$, além de

\footnotetext{
9 Pesquisa em amostra das populações de mais de 80 países sobre valores sociais e políticos, entre outros temas, com dados captados por entrevistas diretas. Realiza-se desde 1981 e já foram concluídas cinco ondas. Para o Brasil, há dados para as ondas de 1990, 1995 e 2005. A base do questionário é a mesma em todos os países, o que permite a comparabilidade. Para maiores detalhes sobre essa pesquisa mundial, ver: <www.worldvaluessurvey.org> A autora fez a coordenação do trabalho de campo da equipe do Centro de Pesquisa de Opinião Pública da Universidade de Brasília - DATAUnB, que realizou o levantamento no Brasil na onda de 2005/2006, tendo, por esse motivo, acesso aos dados mais recentes de todos os países participantes.

10 IBGE (www.ibge.gov.br); Instituto Nacional de Estadística de España (www.ine.es); U.S. Census Bureau (www.census.gov).
} 
pesquisas desenvolvidas com a população idosa no Brasil, na Espanha e nos Estados Unidos.

\section{Saúdes física e emocional}

A primeira comparação de dados oficiais foi sobre a expectativa de vida, a partir de dados para os anos 1940, 2000 e o dado mais recente de cada país. Em 1940, comparadas à expectativa de vida dos norte-americanos, de 63 anos, a do Brasil, 42 anos, era 34\% menor e a da Espanha, 50 anos, era 20\% menor. Em 2000, essas diferenças se reduziram: a expectativa de vida espanhola ( 78,5 anos) ultrapassou a norte-americana (77 anos) e a brasileira era $11 \%$ menor que a dos dois países. Pelo dado mais recente, a Espanha segue com a maior esperança de vida (79,3 anos), seguida de perto pelos Estados Unidos (77,8 anos) e a do Brasil é apenas $6 \%$ menor do que ambas (72,4 anos).

Essa expectativa - um importante indicador de qualidade de saúde - mostra que as diferenças estão diminuindo e que, nos três países, ocorreram os avanços na saúde do idoso. Os dados confirmam a tese de Pérez Díaz, sobre a queda na mortalidade em todas as idades que permitiu o aumento na quantidade e na proporção de pessoas que chegam à velhice em condições cada vez melhores.

Ainda com base em dados oficiais, verifica-se que a auto-avaliação do estado de saúde da população idosa vem melhorando ao longo do tempo nos três países. No Brasil, de 1998 para 2003, o percentual de pessoas de 65 anos ou mais que avaliou a própria saúde como boa ou muito boa aumentou de $37 \%$ para $41 \%$. Na Espanha, dados de 2003 e 2006 foram semelhantes aos brasileiros, tendo ocorrido ligeira queda de $38 \%$ para $37 \%$. O único dado obtido para os Estados Unidos é de 2001, quando o percentual foi o maior, de $66 \%$, ou seja, dois terços dos idosos americanos avaliaram bem a própria saúde.

Aqui se percebe que a satisfação com a própria saúde na população idosa da Espanha foi semelhante ao Brasil. Nos dois países a maior parte dos idosos considerou sua saúde como regular (mais de 40\%) e a menor parte avaliou sua saúde como ruim (em torno de $20 \%$ ). Nesse aspecto, os dados dos idosos norteamericanos foram mais positivos.

No WVS foi feita uma pergunta no mesmo sentido. Os resultados, mais uma vez, demonstram que a melhor avaliação da saúde entre os idosos ocorreu nos Estados Unidos, considerando 1995 e 2005. No mesmo período, a melhoria mais significativa nos dados ocorreu no Brasil, enquanto Espanha e Estados Unidos apresentaram resultados mais estáveis, sendo que a maior parte dos idosos, pouco mais de $40 \%$, avaliou sua saúde como boa ${ }^{11}$. No Brasil, cresceu bastante o

11 Apenas para complementar, foram analisados dados da "Encuesta de calidad de vida de los mayores", do IMSERSO (Instituto de Mayores y Servicios Sociales), órgão do governo espanhol, realizada 
percentual dos idosos que consideram sua saúde boa (34\% para $41 \%$ ), caindo o percentual dos que avaliaram como regular (47\% para $42 \%$ ).

O nível de otimismo para com a vida tem relação com a autopercepção sobre o estado de saúde. Quanto melhor a avaliação do estado de saúde, maior o grau de satisfação com a vida ${ }^{12}$. Os piores resultados ocorreram sempre na Espanha (média de 6,45 em 1995 e 6,86 em 2000), que foram menores ${ }^{13}$ que os do Brasil (7,66 em 1995 e 7,56 em 2005) e dos Estados Unidos (7,92 em 1995 e 7,55 em 2005).

O sentimento de felicidade também está associado à autopercepção sobre o estado de saúde. $\mathrm{O}$ aumento da intensidade do sentimento de felicidade coincide com a melhoria na avaliação do estado de saúde ${ }^{14}$.

A comparação entre os países demonstra que a maior proporção de idosos que se declaram "muito felizes" ocorre sempre nos Estados Unidos (49\% em 1995 e 44\% em 2005). As maiores proporções ocorrem na categoria "felizes", tanto na Espanha (68\% em 1995 e 60\% em 2000), quanto no Brasil (71\% em 1995 e 64\% em 2005).

Os idosos declaram-se "muito felizes" em proporções ligeiramente inferiores do que as outras classes de idade na Espanha e no Brasil. Nos Estados Unidos, a proporção de idosos muito felizes é sempre um pouco maior do que nos outros grupos de idade ${ }^{15}$. Cabe salientar que, com poucas exceções, a maioria se declara apenas "feliz" em todas as classes de idade e esse resultado se repete nos três países e em todas as ondas analisadas do WVS.

Segundo os testes de qui-quadrado, houve associação significativa ao nível de $1 \%$ entre classe de idade e sensação de felicidade para a Espanha e o Brasil. No Brasil, devido às frequências de não-idosos "muito felizes" serem maior do que o esperado; na Espanha, porque ocorreram mais idosos "não muito felizes" do que se esperaria. Nos Estados Unidos, essa associação verifica-se apenas na onda de 2005, pois os idosos declararam-se "muito felizes" com mais frequência do que o esperado.

em setembro de 2006 em amostra de idosos de 65 anos e mais de abrangência nacional. Disponível em: $<w w w$.imsersomayores.csic.es/estadistica/encuestas/index.html> Acesso em: [3 mar. 2008]. Os dados dessa pesquisa confirmam que a maior parte dos idosos espanhóis classifica a própria saúde como boa (39\%); o mesmo percentual avaliou sua saúde como regular.

12 Em uma escala de 1 a 10 sobre o grau de satisfação com a vida, foram feitos testes (análise de variância com nível de significância $\alpha=5 \%$ ) para comparar o grau médio em cada categoria de avaliação do estado de saúde (muito boa, boa, regular e ruim). Nos três países, em todas as ondas avaliadas do WVS, foi sistemático resultado proporcional das duas variáveis: quanto melhor a avaliação do estado de saúde, maior o grau de satisfação com a vida.

${ }^{13}$ Conclusão baseada em análises de variância com nível de significância $\alpha=5 \%$.

${ }^{14}$ Conclusões baseadas em testes de associação de qui-quadrado. Todos foram significativos ao nível de $5 \%$ nos testes por país e em todas as ondas avaliadas do WVS.

${ }^{15}$ As faixas de idade adotadas para comparação foram: até 30 anos; 31 a 59 anos; 60 a 64 anos e 65 anos e mais. 
Os dados não indicam, portanto, que a sensação de felicidade seja muito menor entre os idosos em comparação aos mais jovens. Nos Estados Unidos, ao contrário, esse segmento declara-se "muito feliz" com mais frequência do que os demais. Esse resultado também confirma a melhoria da qualidade de vida do segmento idoso da população, como parte da melhoria das condições de vida de modo geral.

\section{Escolaridade}

Segundo dados dos dois últimos censos demográficos brasileiros, 1991 e 2000, o número médio de anos de estudo da população de 60 anos e mais aumentou um pouco, de 2,9 para 3,2. O percentual de idosos sem escolaridade ou com escolaridade mínima também caiu, de $46 \%$ para $37 \%$. Por outro lado, o percentual com nível de escolaridade superior aumentou de $2 \%$ para $4 \%$. Ainda não são bons dados de escolaridade, mas indicam tendência de melhoria.

$\mathrm{Na}$ Espanha, a tendência é a mesma. Também a partir de dados de censos demográficos, havia, em 1991, $55 \%$ dos idosos sem escolaridade ou com escolaridade mínima e, em 2001 , eram $41 \%$ na mesma situação. 0 percentual de nível superior subiu de 3\% para $4 \%$ no mesmo período.

Finalmente, nos Estados Unidos, a ausência de escolaridade ou escolaridade mínima era de 2\% dos idosos em 1990 e em 2000. O nível superior era de 27\% em 1990, subindo para 30\% em 2000. São dados bastante melhores que os de Espanha e Brasil, e que também demonstram tendência de melhoria.

Os dados do WVS mostram a superioridade comparada dos Estados Unidos com relação a esses indicadores no tempo, mas como as novas gerações apresentam números melhores de escolaridade nos três países, pode-se antever a melhoria da escolaridade dos idosos no futuro.

Inserção no trabalho e renda de trabalho

Da população de 60 anos e mais no Brasil, 25\% eram economicamente ativos em 1991 e, em 2000, eram 23\%. A maior parte, em torno de 40\%, pertencente à faixa de 60 a 64 anos de idade. A partir de 2001, estabiliza-se em torno de $30 \%$ o percentual de idosos economicamente ativos.

Em 2000, 48\% dos idosos ocupados trabalhavam como assalariados e $30 \%$ eram trabalhadores familiares, sem remuneração. Em 2006, 40\% trabalhavam por conta própria; dos idosos aposentados, $19 \%$ estavam trabalhando e $5 \%$ do mercado de trabalho era ocupado por idosos.

$\mathrm{Na}$ Espanha, a situação é bem diferente. Em 1991, 11\% das pessoas de 60 anos e mais eram economicamente ativas. Em 2000 eram 9\% e em 2006, 12\%. Na faixa de 60 a 64 anos a taxa de atividade é de quase $50 \%$, caindo para $5 \%$ a $6 \%$ a 
partir de 65 anos, pelos dados de 2001 a 2005. Da população economicamente ativa em 2006, 5\% eram de pessoas de 60 anos e mais.

Em 2006, a maior parte das pessoas acima de 60 anos trabalha como dirigente de empresa ou da administração pública (17\%); em segundo lugar apareciam os artesãos e trabalhadores qualificados de indústrias manufatureiras, construção e mineração (15\%); $15 \%$ eram trabalhadores não-qualificados. Essas três categorias somavam $47 \%$ dos idosos ativos.

Já nos Estados Unidos, em 1990, a taxa de atividade das pessoas de 65 a 69 anos era de 22\%, e de 7\% entre as pessoas de 70 anos e mais. Em 2000, 21\% dos idosos eram economicamente ativos e, entre esses, $20 \%$ das pessoas com 60 anos e mais estavam trabalhando. Na faixa de 65 a 69 anos a taxa de atividade ainda é alta, de $25 \%$, sendo que $24 \%$ desses estavam trabalhando. Dos $9 \%$ das pessoas de 70 anos e mais economicamente ativas, $8 \%$ estavam trabalhando.

Dados do WVS confirmam essas maiores taxas de ocupação maiores nos Estados Unidos. Em 2005, 15\% das pessoas de 60 anos e mais de idade trabalhavam em tempo integral. No Brasil, eram 7,6\% e na Espanha, 5,8\%. Nos três países, pouco mais de $60 \%$ eram aposentados.

Assim, a principal fonte de renda nos três países entre os idosos é a aposentadoria e, em termos de inserção no trabalho nos Estados Unidos, essa é claramente maior do que no Brasil e na Espanha.

Renda

Em relação à renda, no Brasil, a maior parte dos idosos tem renda de um salário mínimo (53\% em 1991 e 45\% em 2000). Sendo que entre 1991 2000, aumentou o percentual de pessoas de 60 anos e com rendas superiores a um salário mínimo. Em 1991, 6\% tinham renda entre um e cinco salários mínimos e $5 \%$, de mais de cinco salários mínimos. Em 2000, eram 10\% com renda entre um e cinco salários mínimos e $8 \%$, com mais de cinco salários mínimos. Assim, aumentou de $11 \%$ para $18 \%$ o percentual de idosos com renda acima de um salário mínimo.

Segundo o IBGE ${ }^{16}$, a maior parte da renda é proveniente de aposentadorias: $65 \%$ das pessoas de 60 anos e mais e $71 \%$ das pessoas de 75 anos e mais têm essa como a única fonte de renda. Mas há 31\% no grupo acima de 60 anos e 24\% no grupo acima de 65 anos que ainda trabalham e não são aposentados.

$\mathrm{Na}$ Espanha, os idosos possuem boa renda anual, até mesmo se comparados a outros grupos de idade. Em 1996, a renda anual das pessoas de 65

\footnotetext{
${ }^{16}$ Síntese dos Indicadores Sociais: uma análise das condições de vida da população brasileira 2007. Disponíve em:

<http://www.ibge.gov.br/home/estatistica/populacao/condicaodevida/indicadoresminimos/sinteseindic sociais2007/indic_sociais2007.pdf> Acesso em: [2 fev. 2008].
} 
anos e mais era de 5,2 mil euros, chegando a 7,6 mil euros em 2005. Pesquisa do seguro social espanhol (IMSERSO - Instituto de Mayores y Servicios Sociales) informa que $84 \%$ dos espanhóis recebiam aposentadoria ${ }^{17}$.

0 aumento da renda dos idosos maiores de 65 anos ocorreu também nos Estados Unidos. Em 1990, 9\% tinham renda anual de 50 mil dólares ou mais. Esse percentual saltou para 29\% em 2000 e, em 2006, já era de 38\%. A maior parte trabalhava como assalariado, $72 \%$ e 35\% tinham horário flexível. Dos empregados de 65 anos e mais, 3\% tinham mais de um trabalho.

Em uma das perguntas do WVS foi pedido para que o entrevistado classificasse sua renda em uma escala de 1 a 10, levando em conta a realidade de seu país. Na onda de 1995, a média brasileira foi a menor, 2,4, seguida da Espanha, 3,0, e dos Estados Unidos, a maior média, 5,6. Em 2000, a menor média foi a Espanha, 3,3, seguida do Brasil, 4,0, e a maior foi a dos Estados Unidos, 4,8. A renda dos idosos brasileiros aumentou no período analisado. Para os espanhóis e norte-americanos a renda caiu.

A mesma escala, de 1 a 10, foi usada para que as pessoas dissessem o quanto estavam satisfeitas com a situação financeira da família. De 1995 para 2005, os idosos brasileiros mostram-se estáveis, medianamente satisfeitos em relação à situação financeira familiar (médias de 6,7 e 6,1, respectivamente). Contraditoriamente, aumentou a satisfação dos espanhóis ou 5,6 em 1995 e para 6,1 em 2000. A dos norte-americanos, por sua vez, caiu de 7,4 para 6,5.

Pelos dados oficiais, a renda dos idosos aumentou nos três países. Entretanto, apenas no Brasil isso se refletiu na percepção dos próprios idosos. $\mathrm{Na}$ Espanha e nos Estados Unidos, para eles, a renda caiu, assim como a satisfação com a situação financeira da família. Isso mostra que a avaliação subjetiva não reflete as melhorias que, de fato, estão ocorrendo. Ou ainda, pode-se levantar a hipótese de que a melhoria das condições objetivas torna as pessoas mais exigentes, o que tem seu lado altamente positivo, pois denota reflexão e proatividade em vez de acomodação.

\section{Papel social}

Um dos principais aspectos da inserção social do idoso é o seu papel familiar. Cada vez mais, os idosos têm prolongado sua participação no mercado de trabalho, por força inclusive do aumento das restrições às aposentadorias (hoje consideradas) precoces, e também sua atividade como membro importante na família: as aposentadorias representam fator crucial de manutenção das necessidades básicas de toda a família, como provedor ou colaborador, além da

${ }^{17}$ Encuesta de Condiciones de Vida de las Personas Mayores, 2006. Disponível em: <http://www.imsersomayores.csic.es/estadisticas/encuestas/> Acesso em: [3 fev. 2008] 
ajuda na estruturação dos lares e cuidados com os membros dependentes, como crianças e pessoas muito idosas que demandam assistência permanente.

Nos três países, nos últimos anos, o percentual de idosos chefes de família ficou em torno de 20\%. No Brasil, em 1991, $18 \%$ dos idosos eram chefes de família; em 1990, eram 20\%, chegando a $21 \%$ em 2006. Em números absolutos, em 2006 havia o dobro de idosos chefes de família em relação a 1991 (de 6 para 12 milhões, segundo o IBGE).

$\mathrm{Na}$ Espanha, caiu a proporção de idosos chefes de família, mas os percentuais são um pouco mais altos do que os do Brasil e dos Estados Unidos. Em 1991, 36\% dos chefes de família tinham 60 anos e mais, e 26\% tinha 65 anos e mais. Em 2001, eram 26\% de chefes de família com 60 anos e mais e 20\% com 65 anos e mais. Entretanto, foi grande o aumento em números absolutos. De 4 milhões em 1991 para 11 milhões em 2001, considerando o corte em 60 anos e de 3 milhões em 1991 para 8 milhões em 2000, cortando em 65 anos.

Como no Brasil, nos Estados Unidos, embora o percentual esteja estabilizado em torno de $20 \%$, o número absoluto de idosos chefes de família cresceu de 20 milhões em 1990 para 22 milhões em 2000 atingindo 24 milhões em 2006.

Outros aspectos das relações familiares, no caso brasileiro, podem ser obtidos por meio de pesquisa da Fundação Perseu Abramo ${ }^{18}$. Os afazeres domésticos, principalmente cozinhar (29\%), fazer limpeza (12\%), consertos ou reparos (8\%) e as compras (7\%) são as atividades mais frequentes. Ademais, $89 \%$ dos idosos, têm netos. No caso daqueles do sexo masculino, $50 \%$ ajudam nos cuidados com os netos, sendo a maior parte nos finais de semana (12\%) e $11 \%$ são responsáveis por sua criação. Entre as mulheres idosas, $66 \%$ ajudam a cuidar dos netos, sendo que $20 \%$ os criam e $14 \%$ cuidam deles uma parte do dia.

A maioria dos idosos (64\%) considera que tem muita responsabilidade nas atividades do dia-a-dia e, para $82 \%$ deles, isso é considerado muito bom. Sobre a frequência com que os familiares costumam pedir sua opinião, $18 \%$ responderam que isso nunca ocorre. A maior parte, 39\%, declarou que os familiares sempre pedem a sua opinião, denotando bom grau de interação com a família. Confirma isso o fato de $80 \%$ se sentirem totalmente à vontade em relação à sua família. Para $49 \%$ deles, as relações familiares são harmônicas e, para outros 35\%, as relações familiares são afetuosas.

18 "Idosos no Brasil: vivências, desafios e expectativas da $3^{a}$ idade" Fundação Perseu Abramo, SESC/SP, SESC Nacional, Maio de 2007. Pesquisa com amostra de idosos e não-idosos de abrangência nacional. Disponível em: <http://www2.fpa.org.br/portal/modules/news/index.php?storytopic=1642> Consulta em: [16 maio 2007] 
Também na Espanha, em 2006, foi feita uma pesquisa com os idosos de 65 anos e mais ${ }^{19}$. A maioria, $56 \%$, vive com suas famílias. Os afazeres domésticos também são atribuições comuns dos idosos: $50 \%$ lavam a roupa; $36 \%$ fazem pequenos consertos em casa; $52 \%$ fazem as compras; $42 \%$ fazem a limpeza; $51 \%$ administram o lar; $53 \%$ cozinham; e 36\% cuidam de pessoas doentes em casa. Em relação às atividades diárias, os idosos espanhóis majoritariamente, declaram que não têm muitas obrigações, mas que seu tempo está ocupado (60\%).

Os idosos mantinham relacionamento habitual com todos os filhos em $85 \%$ dos casos, com todos os irmãos, $76 \%$, com todos os cunhados, $71 \%$, e com todos os netos, $79 \%$. Os dados indicam serem também os casos de relações diárias com algum dos filhos (62\%) ou com algum neto (47\%).

Mesmo assim, a maioria dos idosos espanhóis (55\%) considerou que, hoje, a atenção dos filhos para com seus pais piorou em relação ao passado. Contraditoriamente, $64 \%$ declararam-se muito satisfeitos com as relações com seus filhos; $60 \%$ disseram estar satisfeitos com o apoio recebido das outras pessoas e $59 \%$ estavam satisfeitos com a própria vida. Ainda, $51 \%$ disseram estar satisfeitos com a forma como utilizavam seu tempo.

Tinham pelo menos um neto $88 \%$ dos idosos. A maior parte ou já cuidou de netos no passado (47\%), ou cuidava de netos na ocasião da pesquisa (25\%), perfazendo $72 \%$ dos idosos envolvidos com essa atividade. Em $43 \%$ dos casos, e em várias vezes por semana, $31 \%$.

A pessoa em quem mais confiavam eram o cônjuge (56\%) e, em seguida, os filhos (30\%). Verificando este resultado por sexo, observa-se que os idosos homens confiavam sobretudo nas esposas ( $77 \%$ ), enquanto as idosas confiavam mais nos filhos, $43 \%$, e depois nos maridos, $40 \%$. Apenas $1 \%$ declarou que não confiava em ninguém.

Não raras são as interações com pessoas que necessitam de alguma assistência, além das relações familiares. Durante os 12 meses que antecederam a pesquisa, $11 \%$ dos idosos ajudaram alguém nos cuidados pessoais (lavar-se, vestir. se ou se deitar); $14 \%$ ajudaram em afazeres domésticos (trabalhos no lar, compras, pequenas arrumações, cuidados com jardins etc.); $12 \%$ ajudaram com papéis, problemas bancários etc.; e $27 \%$ fizeram companhia a alguém necessitado.

O conjunto desses dados, obtido a partir das respostas dos próprios idosos na Espanha, deixava claro que, a despeito de algumas queixas, há bastante interação social, seja com a família ou com outras pessoas. E fica confirmada a

19 "Encuesta de calidad de vida de los mayores", IMSERSO (Instituto de Mayores y Servicios Sociales), órgão do governo espanhol, setembro de 2006. Pesquisa em amostra de idosos de 65 anos e mais, de abrangência nacional. Disponível em: <www.imsersomayores.csic.es/estadistica/encuestas/index.html> Disponível em: [3 mar. 2008]. 
importância do idoso como fator de estrutura familiar e como um segmento bastante ativo no seio da sociedade.

Em suma, os dados para os três países evidenciam o compartilhamento de características positivas e negativas, de atividade e dependência, enfatizando mais a primeira. $O$ estudo dos dados sobre o papel social está é aqui considerado como a principal comprovação da dualidade associada ao papel social do idoso. A pesquisa da Fundação Perseu Abramo com idosos e não-idosos brasileiros também é prova disso ${ }^{20}$. Ao mesmo tempo em que os dados demonstram a atividade e a interação social, uma das conclusões é que, embora, de modo geral, a imagem da velhice seja mais negativa do que positiva, "está longe de ser apenas negativa, sobretudo na perspectiva da população idosa, que percebe tanto aspectos negativos quanto positivos em sua condição." E que há "um forte preconceito social contra a pessoa idosa, ao mesmo tempo em que os idosos avaliam que ser da $3^{a}$ idade hoje é melhor do que já foi ser idoso ou idosa na época em que eram mais jovens."

Da mesma forma, a contradição entre considerar que o trato com os idosos é pior do que antes, no caso dos espanhóis, e apresentar avaliações positivas em diversos aspectos de sua vida é outro fator que comprova a transição da imagem da velhice, que marca a dualidade de seus papéis sociais.

Além disso, pode-se afirmar que há uma interdependência do papel do idoso na sociedade. Embora tentemos aqui ressaltar sua importância na dinâmica social pelo aspecto positivo, são inegáveis os comprometimentos oriundos com o avanço da idade e a necessidade de receber cuidados e atenção a partir de determinado período da velhice, quando a independência fica tolhida pela perda de diversos aspectos funcionais.

De todo modo, os indicadores mostrados até aqui apontam que houve melhorias significativas nos três países, tanto nas condições objetivas quanto na inserção social do segmento idoso. Na continuação, serão analisadas suas atitudes em relação a padrões de comportamento, conceitos e valores sociais, sempre comparando Brasil, Espanha e Estados Unidos e cotejando os dados com aquele da população não-idosa.

\section{Valores sociais}

Com base em dados sobretudo do WVS, o objetivo desta seção é mostrar o quanto os valores do segmento idoso diferem dos demais grupos de idade e, paralelamente, em que medida os países se distinguem ou se assemelham e em

20 Idosos no Brasil: vivências, desafios e expectativas da $3^{a}$ idade. Fundação Perseu Abramo, SESC/SP, SESC Nacional. Maio de 2007. Pesquisa em amostra de idosos e não-idosos de abrangência nacional. Disponível em: <http://www2.fpa.org.br/portal/modules/news/index.php?storytopic=1642> Acesso em: [16 maio 2007] 
quais aspectos. Para mostrar as mudanças no tempo, são tomados dados de 1995 e 2005 para Brasil e Estados Unidos e 1995 e 2000 para a Espanha.

Primeiramente, são tratados os dados sobre valores relacionados a família, casamento, educação de crianças e importância do trabalho. Em seguida, opiniões sobre a tolerância a minorias e grupos sociais específicos, exemplificando com homossexuais e grupos étnicos. Dados sobre igualdade de gênero e religiosidade também foram analisados. As posturas sobre questões éticas e os valores morais, como aborto e eutanásia, completam o quadro de valores sociais dos idosos aqui analisados. Por último, foram analisados dados sobre atitudes em relação à política.

Valores associados à família e casamento

A família se mantém como um forte valor em todas as idades e nos três países. Em nenhum grupo de idade e em nenhum dos países o percentual de pessoas que consideram a família muito importante foi menor que $70 \%$. No Brasil, o menor percentual dos que consideram a família muito importante ocorreu entre os de 60 a 64 anos, em 2005 (79\%). Em todos os grupos de idade, os percentuais entre 1995 e 2005 caíram no Brasil mostrando que houve, uma redução geral no grau de valorização da família no país. É interessante constatar que, ao contrário do que se poderia esperar, os mais jovens atribuíram muita importância à família mais frequentemente do que os mais velhos, tanto em 1995 quanto em 2005.

$\mathrm{Na}$ Espanha, ocorre o contrário: o percentual dos que consideram a família muito importante aumenta com a idade. Entre 1995 e 2000 os percentuais foram semelhantes e um pouco menores do que os de Brasil e Estados Unidos. Os percentuais variam de $75 \%$ a $89 \%$, em 1995, e de $76 \%$ a $90 \%$, em 2000.

Comparados os brasileiros e espanhoís, os norte-americanos são os que mais frequentemente valorizam a família, pessoas consideraram a família "muito importante". Comparados por grupos de idade, os percentuais variaram muito pouco, o que permite dizer que a família é um valor que não mudou com a idade e nem variou no tempo nos Estados Unidos.

Uma das perguntas do WVS foi concordar ou não com a afirmativa de que o casamento é uma instituição ultrapassada. Os dados do Brasil não indicaram tendência associada ao aumento da idade, em que os mais velhos tenderiam a discordar mais frequentemente dessa afirmativa, como ocorreu na Espanha e nos Estados Unidos, tanto em 1995 quanto em 2000 e 2005. O Brasil apresenta os maiores percentuais de concordância, em torno de $20 \%$, e os Esatos Unidos, os menores, aproximadamente $10 \%$. Deve-se ressaltar que a concordância foi minoritária em todos os grupos de idade dos três países, nas duas ondas do WVS. $\mathrm{Na}$ Espanha, aumentou muito entre os mais jovens a ideia de que o casamento é 
uma instituição ultrapassada, de 20\% em 1995 para 33\% em 2000. Foi o único dado que se alterou significativamente. No restante, os dados ficaram mais ou menos estáveis. No conjunto, os dados indicam que não se alterou muito a ideia sobre a instituição do casamento, que permanece forte nos três países e também em todas as faixas de idade.

Por outro lado e contraditoriamente, é expressiva a aprovação da decisão da mulher de ter filhos sem se casar, o que se convencionou chamar, no Brasil, de "produção independente". Nos três países, entre os mais jovens, a maioria aprova a "produção independente". Na Espanha, a aprovação ultrapassa os $80 \%$ entre as pessoas com até 30 anos. À medida que a idade avança, a aprovação cai, na Espanha mantém-se com a mais alta frequência de aprovação. Brasil e Estados Unidos mantiveram-se mais similares nesse tema, embora a aprovação no Brasil tenha sido ligeiramente menor em todas as faixas de idade.

\section{Tolerância/Intolerância a grupos sociais}

Um aspecto que é comumente adotado como indicador de avanço nas relações sociais diz respeito à aceitação da diversidade e das mudanças em relação ao comportamento tradicional. Uma sociedade é considerada avançada ou moderna na medida em que essas diferenças passam a não ser mais rejeitadas e se incorporam ao cotidiano em convivência pacífica e respeitosa. Os exemplos são inúmeros, homossexuais, grupos étnicos, imigrantes, entre outros, reivindicam seu espaço na sociedade e a eliminação do que seriam preconceitos em relação à sua presença e ao seu modo de viver.

Essas questões fizeram parte do WVS e são analisadas para verificar se a atitude dos idosos se distingue dos outros grupos de idade. Foi pedido que os respondentes indicassem tipos de pessoas que não gostariam de ter como vizinhos. Nesta análise, são comentados os dados de aceitação ou rejeição ao homossexualismo e a pessoas de grupos étnicos distintos do ao entrevistado ${ }^{21}$.

No caso do homossexualismo, observa-se que a rejeição caiu nos três países entre 1995 e 2005, e foi minoritária em todos os casos. Os mais baixos níveis de rejeição ao homossexualismo ocorreram na Espanha, enquanto Brasil e Estados Unidos tiveram resultado semelhante, de rejeição mais forte. 0 percentual mais alto ocorreu entre os norte-americanos de 65 anos e mais, 40\%. Nos três países, os mais velhos apresentam maior rejeição 22 . Portanto, observa-se um comportamento mais conservador dos mais idosos em relação ao homossexualismo nos três países e em todas as ondas analisadas.

\footnotetext{
${ }^{21}$ A pergunta menciona "pessoas de outras raças".

22 Testes de qui-quadrado comprovam associação significativa da rejeição ao homossexualismo em função do aumento da idade ao nível de significância de 5\% no Brasil e 1\% para Espanha e Estados Unidos.
} 
Em outra pergunta sobre o mesmo tema, utilizou-se uma escala de 1 a 10 para saber o quanto se justifica o homossexualismo. Quanto menor a média, menos se justifica na visão do conjunto de respondentes. No Brasil, as médias das respostas são as mais baixas, denotando a menor tolerância dos três países. E a dos mais velhos é ainda menor, mas não o bastante para que a diferença seja estatisticamente significativa ${ }^{23}$, nem em 1995, nem em 2005. Na Espanha, as diferenças foram significativas em todos os grupos de idade, e todos foram significativamente diferentes entre si nas duas ondas, de 1995 e de 2000: quanto maior a idade, menos se considera que o homossexualismo se justifica. Nos Estados Unidos também houve diferenças significativas, embora os mais jovens tenham posições equivalentes entre si, mas mais tolerantes do que os mais velhos, que também foram semelhantes entre si.

Os dois resultados indicam que a rejeição ao homossexualismo é maior entre os idosos, embora esteja caindo em todos os grupos de idade e nos três países. Assim, percebe-se que houve uma evolução no sentido de aceitação do homossexualismo, mas que os idosos permanecem mais conservadores do que os mais jovens nesse tema.

A rejeição a pessoas de outros grupos étnicos, por outro lado, é muito baixa nos três países. No Brasil e nos Estados Unidos, não chega a 10\%. Na Espanha, aumenta com a idade, mas também é sempre menor do que $15 \%$ entre os idosos.

O WVS inclui uma extensa lista de grupos sociais específicos que permitiriam fazer outras análises. Entretanto, os dois temas destacados são suficientes para demonstrar que ainda há diferença nos aspectos de tolerância a diferenças de comportamento, sendo os mais velhos menos receptivos que os mais jovens, embora o importante seja constatar que há uma evolução em curso no rumo do aumento da tolerância, e que isso ocorre também no segmento dos mais idosos.

Igualdade de gênero

Analisamos nesta seção as opiniões sobre a da inserção da mulher na vida de sua sociedade, eliminando as barreiras de acesso e comportamento tradicionalmente livres para os homens. Uma das barreiras iniciais em superação é a inserção no mercado de trabalho. O WVS trata desse tema por meio de um conjunto de perguntas, das quais foi destacada uma sobre a concordância em dar prioridade de emprego aos homens em casos de crise e escassez de trabalho. Mais uma vez, nos Estados Unidos ocorreu o menor grau de concordância, seguido de Espanha e Brasil, nessa ordem, embora quase todos os percentuais tenham sido baixos. Apenas entre os maiores de 65 anos no Brasil, em 1995, 62\% concordaram com isso.

${ }^{23}$ Conclusões baseadas em análises de variância. 
Nas ondas mais recentes, o maior percentual de concordância foi entre os maiores de 65 anos na Espanha, onde 32\% concordavam que os homens deveriam ter preferência de emprego em casos de crise. Assim, o grau de concordância caiu nos três países, mantendo os Estados Unidos com os percentuais mais baixos. Brasil e Espanha mostraram-se semelhantes nos dados mais recentes. $O$ aumento do grau de concordância com o aumento da idade também se repetiu e, mesmo caindo no tempo, os mais velhos mostraram-se mais conservadores do que os mais jovens nesta questão.

O questionário do WVS também pediu que as pessoas se posicionassem, concordando ou não com a afirmativa de que trabalhar em casa traz tanta realização quanto trabalhar fora e ganhar salário. O princípio adotado para analisar esse posicionameno foi o seseguinte: concordar com isso denota conservadorismo em relação à igualdade de gênero. Os percentuais de concordância entre os mais jovens foram sempre menores nos três países e em todas as ondas de pesquisa. As maiores mudanças da onda de 1995 em relação a ondas mais recentes ocorreram no Brasil. Em 1995, concordavam com isso entre 32\% e 54\%, dos mais jovens para os mais velhos, sendo esses os mais altos percentuais em relação a Espanha e Estado Unidos. Em 2005, os dados mudaram radicalmente, variando de $10 \%$ para $12 \%$ nas faixas de idade, que tiveram resultados muito próximos e passaram a ser os mais baixos. Espanha e Estados Unidos tiveram resultados semelhantes nas duas ondas. Na Espanha, os percentuais variaram de pouco mais de $10 \%$ para pouco mais de 20\%; nos Estados Unidos, de 26\% até 29\% em 1995 e de 30\% até $35 \%$ em 2005, tendo ocorrido pequeno aumento. Se a concordância implica conservadorismo, pode-se dizer que, nos Estados Unidos, houve pequeno retrocesso nesse tema. Mais pessoas de todas as idades concordaram que o trabalho em casa é tão realizador quanto o trabalho remunerado fora do lar.

Nos temas estudados na questão da igualdade de gênero, o conjunto dos resultados indica que o tradicionalismo está em queda nos três países e que, embora os mais velhos sejam um pouco mais conservadores, também há evolução no sentido de concordar com a igualdade de gêneros. Os dados das ondas mais recentes aproximam os três países nesse tema.

\section{Questões éticas e morais}

Espera-se que o rigor nas questões éticas e morais aumente com a idade, como fruto do processo de amadurecimento pessoal, de construção de atitudes de civilidade e respeito em geral. Espera-se também que haja maior relaxamento no Brasil, conhecido com o "país do jeitinho", e que as pessoas sejam mais tolerantes à burla da lei e ao afrouxamento nas questões de comportamento. 
Para verificar o quanto os países se distinguem e o quanto o aumeno de idade influencia nesses temas, foram observados dados do WVS sobre pedir benefícios sem ter direito, sonegar impostos e aceitar suborno e no campo da ética, sobre prostituição, aborto e divórcio no campo da moral. É parte de uma sequência de variáveis registradas em uma escala de 1 a 10 sobre o grau de percepção sobre o quanto se justificam aquelas atidudes.

Em 1995, no Brasil, em todos os grupos de idade, as médias ficaram em torno de 3,5, exceto para "aceitar suborno", que foi maior $(4,0)$, embora ainda abaixo da média. Foram feitas comparações das médias e apenas no caso sobre aceitação de suborno houve diferenças entre os grupos de idade ${ }^{24}$. Ao contrário do esperado, os mais tolerantes em relação a essa prática foram os idosos acima de 65 anos, com a maior média (5,2). Em 2000, caem as médias para "pedir benefícios sem ter direito" (de 3,2 para 2,7) e aceitar suborno (de 4,0 para 1,9). Nas comparações das médias, foi detectadado que os mais jovens foram mais tolerantes quanto a "pedir benefícios sem ter direito", "sonegar impostos" e "aceitar suborno", embora todas as médias tenham sido muito baixas. Assim, houve uma evolução para melhor no caso brasileiro e, levando em conta o conjunto de respostas, é possível questionar se ainda é tão disseminada a conduta de "país do jeitinho" ou se está havendo melhoria no sentido de observância de normas e de aumento da valorização do comportamento mais ético.

$\mathrm{Na}$ Espanha, em 1995, as médias foram muito inferiores, abaixo de 2,0 para todas as variáveis, demonstrando, já naquela época, pouquíssima tolerância à burla da ética. Na comparação por idade, observou-se que os mais jovens foram mais tolerantes em relação a "evitar pagar transporte público" e "sonegar impostos", devendo-se reforçar que, mesmo entre esses, as médias foram muito baixas. Em 2000, houve pequeno aumento nas médias de todas as variáveis, ficando acima de 2,0, exceto para a variável sobre aceitação de suborno. Em todas, os mais jovens foram mais tolerantes.

Nos Estados Unidos, as médias não mudaram muito de 1995 para 2005 e também foram muito reduzidas - todas ficaram pouco acima de 2,0, exceto para "aceitar suborno", 1,7. Em todas as variáveis, os mais jovens foram mais tolerantes, com médias maiores em relação aos mais velhos nas questões éticas.

Logo, observou-se uma evolução positiva no Brasil que, pelos dados mais recentes, aproximou-se de Espanha e Estados Unidos em relação à baixa tolerância acerca da burla da ética, até mesmo sobre o rigor mais forte entre os mais velhos em algumas questões.

Os dados sobre os temas morais, destacando prostituição, aborto e divórcio, também foram registrados em escalas de 1 a 10 . Pelas médias mais baixas, em

24 Todas as conclusões deste tópico sobre as variáveis relacionadas a questões éticas e morais foram baseadas em análises de variância comparando as médias obtidas em cada grupo de idade. 
1995, o Brasil foi sempre o menos tolerante em todas as faixas de idade. A menor tolerância foi em relação ao aborto, com média de 2,0. A maior média foi com relação a justificativa para o divórcio, 4,9. Foi surpreendente constatar que, entre os grupos de idade, a média mais alta ocorreu entre os maiores de 65 anos, 6,1, enquanto nos outros grupos a média ficou em torno de 4,8. Em 2005, as médias referentes à prostituição e ao divórcio elevaram-se, denotando maior tolerância em relação a 1995. Por outro lado, as opniões sobre aborto tiveram resultados semelhantes aos de 1995, o que demonstra que não houve mudanças nesse aspecto. No caso do divórcio, os resultados foram bem diferentes de 1995 pois, quanto maior a idade, menor a tolerância. As médias variaram de 5,8 para 4,8, dos mais jovens para os mais velhos.

A Espanha, em 1995, teve, em geral, médias um pouco mais altas do que o Brasil. A mais baixa foi para prostituição e a mais alta, para divórcio, acima de seis. Em todas as variáveis, a tolerância caiu com o aumento da idade. No caso do divórcio, a partir de 60 anos a tolerância ficou abaixo da média. 0 mesmo ocorreu para aborto e prostituição. Em 2000, todas as médias aumentaram. A comparação das idades repetiu o resultado para 1995, com queda da tolerância à medida que avança a idade.

Já nos Estados Unidos em 1995, as médias foram um pouco mais baixas do que as de Espanha e maiores que as do Brasil. A maior média foi para o divórcio, 5 ,4. Exceto para o aborto, com relação ao qual as médias para cada idade foram equivalentes, a maior média sempre ocorreu na faixa de 65 anos e mais. Em 2005, as médias aumentaram um pouco, mas a não-tolerância continuou predominando, exceto para divórcio. Nesse caso, não houve diferenças em função da idade. Nas outras variáveis, prostituição e aborto, as médias para pessoas de 60 anos e mais foram menores do que os mais jovens.

Assim, tomando o ponto médio da escala de 1 a 10 como 5,5 e considerando como intolerância os resultados inferiores ao ponto médio e tolerância os resultados superiores, verificou-se que a intolerância predominou nos três países e não mudou muito com o passar do tempo. O Brasil mostrou-se o menos tolerante, com alguma mudança em direção ao aumento da tolerância. Espanha e Estados Unidos tiveram resultados um pouco superiores, mas também predominou a intolerância, não tendo sido observadas mudanças significativas nessas atitudes no período aqui estudado.

$\mathrm{Na}$ comparação das médias dos países por onda, o Brasil, sistematicamente, apresentou os menores valores, os Estados Unidos os valores intermediários e a Espanha os maiores. Assim, embora enha havido pequeno aumento nas médias ao longo do tempo, essa evolução ainda não demonstra aceitação majoritária em relação a esses temas. 
Valores políticos

O último aspecto aqui abordado diz respeito aos valores políticos. O interesse, a importância percebida em relação à democracia e a participação efetiva foram as variáveis do WVS utilizadas para visualizar possíveis as diferenças de atitude e comportamento entre os países e entre os grupos de idade em cada um deles.

Iniciando pelo interesse manifestado pela política, foi destacado o percentual de pessoas que se disseram muito interessadas. Nos três países, tanto em 1995 quanto em 2005, (ou 2000 no caso espanhol), os percentuais entre os grupos de idade não variaram muito, por grupos de idade, mas os percentuais caíram um pouco de uma onda para outra, indicando uma queda no interesse pela política ao longo do tempo.

Entre os países, os Estados Unidos, apresentaram os percentuais mais altos, de $18 \%$ para $11 \%$ de pessoas muito interessadas em política, seguidos do Brasil (13\% para $11 \%$ ) e, com os percentuais mais baixos, a Espanha, cujos percentuais foram da ordem de $6 \%$ nas duas ondas.

Em outra questão, foi pedido que as pessoas dissessem o quanto a política é importante. Os percentuais dos que afirmaram que política é muito importante também caíram ao longo do tempo nos três países. Na comparação entre os grupos de idade, no Brasil e na Espanha o percentual caiu com o avanço da idade, ou seja, os mais velhos atribuem menos importância à política ${ }^{25}$. Nos Estados Unidos, o resultado foi ao contrário: quanto maior idade, maior importância se atribui à política. O Brasil, desta vez, obteve os percentuais mais altos, de 22\% em 1995 para $15 \%$ em 2005, enquanto na Espanha caiu de $8 \%$ para $6 \%$ e, nos Estados Unidos, de $18 \%$ para $11 \%$.

Outro dado sobre atitude em relação à política foi a valorização da democracia, variável que também foi medida em uma escala de 1 a 10. Esse dado estava disponível apenas para Brasil e os Estados Unidos, na onda de 2005. Nos dois países, a importância percebida da democracia cresceu com a idade. Os mais velhos valorizavam mais fortemente a democracia, apesar de em todos os grupos de idade as médias terem sido altas, acima de 7,9. No Brasil, a média foi de 8,0 para 8,2 dos mais jovens para os mais velhos. Nos Estados Unidos, foi de 7,9 para 9,4 . Na comparação das médias no caso brasileiro ${ }^{26}$, a maior ocorreu entre as pessoas de 60 a 64 anos e a menor, entre os de até 30 anos. Nos Estados Unidos, a partir de 60 anos se valoriza mais a democracia do que as faixas de idade mais

\footnotetext{
25 Pelos testes de qui-quadrado, foi detectada associação significativa de importância da política em função da idade nos três países e em todas as ondas de pesquisa.

${ }^{26}$ As comparações de médias foram feitas por análise de variância.
} 
novas. Assim, a democracia é um valor mais forte entre os mais velhos, tanto no Brasil quanto nos Estados Unidos.

O estudo da participação efetiva foi feito verificando o percentual de membros ativos de partidos políticos. A participação ativa na política é sistematicamente baixa. A Espanha teve os menores percentuais, de $2 \%$ para menos nos grupos de idade. No Brasil, foi de $6 \%$ para $13 \%$ dos mais jovens para os mais velhos em 1995 e não passou de $7 \%$ em 2005 e ficou estável por grupos de idade. A maior participação como membro ativo de partido político ocorreu nos Estados Unidos. Em 1995, foi de $18 \%$ para $22 \%$ dos mais jovens para os mais velhos. Em 2005, caiu de $12 \%$ até $20 \%$. Assim, quando houve diferenças, os percentuais maiores ocorreram entre os mais velhos, ao contrário do esperado.

Portanto, em termos de atitudes em relação à política, os idosos não apresentam grande diferença em relação aos grupos mais jovens. Em alguns casos os idosos tiveram resultados até mais favoráveis do que os mais jovens, na valorização da política e da democracia e na expectativa de ação do Estado para garantir boas condições de vida e no grau um pouco mais alto de participação ativa em partidos políticos.

\section{Conclusão}

O processo de mudança na estrutura etária das populações, com o aumento da idade média, reduções da natalidade e da mortalidade em todas as faixas etárias, é fenômeno irreversível. Já se consolidou nos países de economia mais desenvolvida, está em curso acelerado nos países em desenvolvimento e tende a se instalar no restante do mundo, devendo tornar-se uma característica comum, planetária, em um futuro não muito distante. Há registros desse processo desde finais do século XIX, sendo que a ênfase inicial foi de abordagens negativistas, que antecipavam consequências deletérias para uma humanidade envelhecida a partir dos conceitos negativos que predominavam sobre o indivíduo de idade avançada. Não poderia ser diferente pois, até meados do século XX, o segmento idoso das populações era formado principalmente por pessoas com sérias limitações de saúde, pouca educação, em geral mais pobre e dependente, um peso para famílias e governos. Tanto era assim que as primeiras iniciativas das sociedades e dos governos foram no sentido de constituir instituições de abrigo permanente para esse segmento.

A discussão sociológica é mais recente e tem convivido com análises de abordagem fortemente economicista. As análises que objetivavam explicar o fenômeno da mudança demográfica enfatizavam a redução da natalidade, um desvio de foco acertadamente detectado pelo espanhol Julio Pérez Díaz em seus diversos trabalhos sobre o assunto. A esse autor se credita, neste artigo, a principal 
contribuição para compreender a mudança demográfica. Ele argumentou que a redução da natalidade ocorreu junto com a queda da mortalidade em todas as faixas de idade, não apenas a mortalidade infantil. As pessoas passaram a viver mais devido a avanços nos conhecimentos, não apenas da medicina, mas também de saúde pública, de nutrição e produção de alimentos, além da disseminação da educação escolar, que passou a atingir as camadas populares, para atender às exigências de uma nova economia e de um mercado que se globalizava. Como consequência, não era mais necessária uma grande quantidade de descendentes para a continuidade das famílias. Pérez Díaz chamou esse processo de eficiência reprodutiva que ocorreu concomitantemente ao que ele denominou de democratização da sobrevivência.

Essa conjunção de fatores acabou gerando uma nova configuração social, mais racional e reflexiva, na qual diversos fatores da existência passaram a ser objeto de planejamento, incluindo a quantidade de filhos. Nessa nova configuração, há a redução do tamanho da prole, a entrada da mulher no mercado de trabalho, o alargamento dos conceitos sobre o comportamento de um modo geral e o desenvolvimento tecnológico. Tudo isso afeta a forma como as pessoas se relacionam.

Nos trabalhos aqui abordados, foi observado um esforço de retirar as interpretações negativistas sobre a velhice e resgatar um tratamento de respeito. Entretanto, a maior parte desses trabalhos está eivada de novas prescrições sobre o comportamento do idoso. Passa-se a exigir dele disposição e esforço para ser feliz, ativo e participante com o propósito de evitar os "sintomas" de envelhecimento, como recolhimento e introspecção. Assim, em clara referência à vida dos mais jovens, passou-se a prescrever um estilo de comportamento jovial sem alternativas, mais uma vez enredando o idoso em uma teia de conceitos que, no fundo, continuam rejeitando a velhice e o envelhecimento.

Em outra vertente, fica claro que o idoso, ao manter-se no mercado de trabalho por mais tempo por estar vivendo mais e em melhores condições, por um lado, e em virtude da ampliação do acesso aos benefícios previdenciários que the garante a renda mensal, por outro, vem aumentando sua importância nos arranjos familiares. Seja contribuindo economicamente, seja auxiliando na organização doméstica pelos cuidados com o lar e com crianças, passa a ser uma peça importante nas famílias, e não mais um peso ou um estorvo.

Assim, a inserção social do idoso vive uma transição claramente registrada na literatura revisada. Por isso, no título deste artigo, classificamos a relação social do idoso como dual. As melhorias pessoais e sociais convivem com o contraponto de dependência e desencaixe social devido a limitações de ordem física e mental. Espera-se que esse estágio atual de percepção evolua para que a dependência e o desencaixe deixem de ser vistos de maneira depreciativa, por ser inexorável, para 
que a velhice, paulatinamente, seja aceita como algo natural, apenas como mais um estágio da vida humana. E espera-se que esse estágio seja atingido pela maior parte da população.

$\mathrm{Na}$ análise de dados, ficou demonstrado por vários caminhos que, em diversos temas, as percepções dos idosos não se distinguem tanto ao dos demais grupos de idade. Ficou demonstrado também que seus conceitos estão mudando ao longo do tempo. A despeito de demonstrarem maior conservadorismo em algumas questões em relação aos mais jovens, mudanças estão ocorrendo. A comparação das posições dos mais velhos em relação aos demais permite concluir que os aspectos em processo de mudança nas sociedades estão sendo absorvidos, alguns mais rapidamente que outros. O mais importante foi notar que o sentimento de felicidade e de satisfação com a vida é forte entre os idosos sendo, em alguns casos, até maior do que em outros grupos de idade.

A comparação entre os três países, Brasil, Espanha e Esados Unidos, também não apontou uma única regra ou direção. Ora o Brasil é semelhante à Espanha, ora aos Estados Unidos, ora difere dos dois, ora Espanha se aproxima dos Estados Unidos. Assim, considerando que o Brasil é classificado como um país em desenvolvimento e que Espanha e Estados Unidos, como desenvolvidos, conclui-se que não é o fator econômico que define o rumo de evolução dos conceitos sociais e políticos ou torna os idosos dos países desenvolvidos mais "modernos" do que os brasileiros, e vice-versa.

Por outro lado, tampouco as tradições católicas, que marcam as culturas espanhola e brasileira, aproximam os dois países em suas posições morais e também não os distanciam de percepções que predominam na sociedade norteamericana. Também nesses temas, as semelhanças e diferenças não seguiram padrões detectáveis.

Dados objetivos confirmam as melhorias nas condições de vida dos idosos nos três países. Seja na saúde ou na situação econômica, até mesmo no Brasil os idosos hoje se encontram em melhor situação do que no passado.

As análises de dados confirmaram largamente a literatura, principalmente no que concerne a esse último aspecto, de melhoria das condições de vida em geral. Quanto à inserção social, os dados também confirmaram um processo de aproximação de percepções em relação aos demais grupos de idade e que não seguem padrões atribuíveis à situação econômica ou a aspectos de tradição cultural.

Finalmente, o que está faltando para ultrapassar a dualidade, ou seja, o que é necessário evoluir na transição da percepção social em relação ao idoso, por não fazer mais sentido prático, é retirar definitivamente a referência do idoso no segmento mais jovem. O grupo de pessoas mais velhas tem características múltiplas, mas específicas. Trata-se de um segmento que não está estagnado no 
tempo. As mudanças ficaram bem demonstradas nas análises de dados, tanto em questões objetivas, quanto subjetivas. Assim, esse segmento social, cada vez mais importante e numeroso, merece o desenvolvimento de uma abordagem específica e livre das ambiguidades que marcam o discurso sobre o envelhecimento.

\section{Referências Bibliográficas}

BORGES, M. C. M. O idoso e as políticas públicas e sociais no Brasil. In: SIMSOM, O. R. de M.; CACHIONI, M.; NERI, A. L. (org.). As múltiplas faces da velhice no Brasil. Campinas: Alínea, 2006.

CAMARANO, A. A. "Envelhecimento da população brasileira: uma contribuição demográfica." Texto para discussão. Rio de Janeiro: IPEA, n 858, p. 1-31 Jan. 2002.

DEBERT, G. G. "A invenção da terceira idade e a rearticulação de formas de consumo e demandas políticas." Revista Brasileira de Ciências Sociais. São Paulo. v. 12. $n^{\circ}$ 34. p. 39-56, 1997.

DEBERT, G. G. O velho na propagando. Cadernos Pagu. Campinas: Núcleo de Estudos de Gênero/PAGU/UNICAMP, n²1, p. 133-155, 2003.

ESSMAN, E. American attitudes toward the elderly. [Online]. Disponível em: <http://www.lifeintheusa.com/aging/attitude.htm>. Acesso em: [22 jun. 2007].

FOGEL, R. W. Biotechnology and the Burden of Age-Related Diseases. [Online] Disponível em :

<http://cniss.wustl.edu/workshoppapers/FogelBiotechnologyLecture.pdf $>$. Acesso em: [24 fev. 2008].

FOGEL, R. W. Changes in the process of aging during the twentieth century: findings and procedures of the early indicators project. Population and Development Review, New York, v. 30, Supplement: Aging, Health, and Public Policy. p. 19-47, 2004.

GOLDANI, A. M. Relações intergeracionais e reconstrução do Estado de Bem-Estar: Por que se deve repensar essa relação para o Brasil? In: CAMARANO, A. A. (Org.). Os novos idosos brasileiros: muito além dos 60? Rio de Janeiro: IPEA, 2004.

LEIBING, A. "The old lady from Ipanema: changing notions of old age in Brazil." Journal of Aging Studies. Amsterdam, n 19, 2005. p.15-31, 2005. 
LOPES, A. Dependência, contratos sociais e qualidade de vida na velhice. In: SIMSOM, O. R. de M.; CACHIONI, M.; NERI, A. L. (orgs.). As múltiplas faces da velhice no Brasil. Campinas: Alínea, 2006.

MASCARO, S. de A. O que é velhice. São Paulo: Brasiliense, 2004.

NAJBERG, S.; IKEDA, M. Previdência no Brasil: desafios e limites. Publicações BNDES, 10/1999. [Online]. Disponível em <http://www.bndes.gov.br/conhecimento/livro/eco90_08.pdf>. Acesso em: [10 mar. 2008].

ONU. Consejo Económico y Social. Principales acontecimientos en la esfera del envejecimiento desde la Segunda Asamblea Mundial sobre el Envejecimiento. Informe del Secretario General. 21 de novembro de 2006.

PAIVA, P. de T. A. e WAJNMAN, S. Das causas às consequências econômicas da transição demográfica no Brasil. Revista brasileira de estudos populacionais. [Online]. v. 22, n² 2, p. 303-322. Disponível em:

$<$ www.scielo.br/scielo.php?script=sci_arttext\&pid=S0102.

30982005000200008\&lng=pt\&nrm=iso>. Acesso em:[ 23 maio 2007]. mar. 2003

"El envejecimiento demográfico y la política." Tardor, Barcelona, n 5, p.1-3.

PÉREZ DÍAZ, J. "Consecuencias sociales del envejecimiento demográfico." Papeles De Economía Española, Transformación Demográfica, Raíces y Consecuencias, Madrid. n 104, p.210-226, jul. 2005.

Demografía y envejecimiento. Madrid, Portal Mayores, InformesPortal Mayores. [Online]. $n^{\circ}$ 51. Lecciones de Gerontología, I [Fecha de publicación: 09/06/2006]. Disponível em:

<http://www.imsersomayores.csic.es/documentos/documentos/perez-demografia01.pdf> Acesso em: [23 abr. 2007].

PNUD Brasil. Coleção Estudos Temáticos sobre os Objetivos de Desenvolvimento do Milênio. Rede de Laboratórios Acadêmicos para o Acompanhamento dos Objetivos de Desenvolvimento do Milênio. PNUD Brasil/PUC Minas, 2007.

PRADO, S. D. e SAYD, J. D. "A gerontologia como campo do conhecimento científico: conceito, interesses e projeto político." Ciência \& Saúde Coletiva, Rio de Janeiro. v. 11. $n^{\circ}$ 2. p.491-501. abr.jun. 2006.

QUEIROZ, B. L.; SAWYER, D. O.; CARVALHO, J. A. M. de; FREITAS, A. J. de; AGOSTINHO, C. S.; MÁXIMO, G. da C. Envelhecimento populacional e os sistemas públicos de suporte aos idosos: o caso brasileiro. In: BRASIL. Ministério do 
Desenvolvimento Social e Combate à Fome. Avaliação de políticas e programas do MDS: resultados: Bolsa Família e Assistência Social. Brasília: MDS - SAGI

(Ministério do Desenvolvimento Social e Combate à Fome - Secretaria de Avaliação e Gestão da Informação). Avaliação de políticas e programas do MDS: resultados; v. 2, 2007.

RODRIGUEZ AVILA, N.; GUILLEN ESTANY, M. STRASSBERG, B. A. 2007. The new responsibilities of social sciences in aging societies: the case of Spain. The International Journal of Interdisciplinary Social Sciences. Melbourne v. 2, $n^{\circ} 1$. p. 213. 228. jan-feb. 2007.

WAITE, L. J. "The demographic faces of the elderly." Population and Development Review, New York, v. 30, Supplement: Aging, Health, and Public Policy. p. 3-16, 2004.

WISE. D. A. "Social Security provisions and the labor force participation of older workers." Population and Development Review, New York. v. 30, Supplement: Aging, Health, and Public Policy. p.176-205, 2004.

WONG, L. L. R. \& CARVALHO, J. A. O rápido processo de envelhecimento populacional do Brasil: sérios desafios para as políticas públicas. Revista Brasileira de Estudos Populacionais [Online]. v. 23, $\mathrm{n}^{\circ}$ 1. p. 5-26. Disponível em:

$<$ www.scielo.br/scielo.php?script=sci_arttext\&pid=S0102.

30982006000100002\&lng=pt\&nrm=iso> Acesso em: [23 maio 2007].

Maria Inez Machado Telles Walter·minez@unb.br

Recebido para publicação em agosto de 2008. Aprovado para publicação em março de 2009. 